\title{
Economic Impact of Etanercept in Patients with Psoriasis and Psoriatic Arthritis in Spain: A Systematic Review
}

\author{
Lluís Puig · Lourdes Rodríguez Fernández-Freire · Ramón Burgos-Pol (D) • \\ Ismael Gomez · Carmen Peral · Susana Gomez · Francisco José Rebollo Laserna
}

Received: March 21, 2019 / Published online: May 6, 2019

(C) The Author(s) 2019

\section{ABSTRACT}

Introduction: Etanercept (ETN), a highly effective biological agent for the treatment of psoriasis (PSO) and psoriatic arthritis (PsA), is widely used in Spain. However, evidence of its economic impact is limited, indicating the need for a systematic review of the economic assessments conducted on the use of ETN in the treatment of both PSO and PsA in Spain.

Methods: A systematic review was carried out in PubMed, Embase, Cochrane Library, Health Technology Assessment reports and not indexed sources up to November 2018. The

Enhanced Digital Features To view enhanced digital features for this article go to: https://doi.org/10.6084/ m9.figshare.8040827.

Electronic supplementary material The online version of this article (https://doi.org/10.1007/s13555019-0301-6) contains supplementary material, which is available to authorized users.

L. Puig

Hospital de la Santa Creu i Sant Pau, Barcelona, Spain

L. R. Fernández-Freire

Hospital Virgen del Rocío, Seville, Spain

R. Burgos-Pol ( $\bowtie)$

Pharmacoeconomics and Outcomes Research Iberia (PORIB), Madrid, Spain

e-mail: rburgos@porib.com

I. Gomez · C. Peral · S. Gomez · F. J. Rebollo Laserna Pfizer S.L.U., Alcobendas, Madrid, Spain inclusion criteria were economic evaluations (total and partial) and dose optimization studies published in English or Spanish on the use of ETN to treat PSO and PsA for ETN in Spain.

Results: A total of 402 publications were identified, of which 32 were selected for inclusion in the review; of these 32 publications, $81.3 \%$ analyzed PSO (14 full economic evaluations, 5 partial economic evaluations and 7 dose optimization studies) and $18.8 \%$ analyzed PsA (1 economic analysis and 5 dose optimization studies). The perspective of the Spanish National Health Service (NHS) was used in $90.0 \%(n=18)$ of the full and partial economic evaluations. The time horizons ranged from 12 weeks to 2 years. Reductions in the Psoriasis Area and Severity Index (PASI) of 50, 75 and 90\% (PASI 50, 75 and 90, respectively) were most commonly used as efficacy outcomes in the complete evaluations. The economic impact of ETN ranged from $€ 9110-14,337 /$ PASI 75 at 12 weeks ( $50 \mathrm{mg} /$ week) to $€ 82,279 /$ PASI 90 at 2 years, depending on the health outcome, time horizon and ETN dose used. Only one study determined the cost of using ETN for the treatment of PSO $(€ 29,430-52,367 /$ QALY for dose $2 \times 25 \mathrm{mg} /$ week or $50 \mathrm{mg} /$ week, respectively). Only one partial economic evaluation on PSA was identified (NHS perspective), resulting in an ETN annual cost of $€ 8585 /$ patient-year.

Conclusion: Consistent evidence on the economic impact of ETN for the treatment of PSO and PSA in Spain is lacking, mainly due to the 
highly heterogeneous methodology used and the broad range of outcomes found in the economic evaluations published to date.

Funding: Pfizer S.L.U.

Keywords: Economic evaluations; Etanercept; Psoriasis; Psoriatic arthritis; Spain; Systematic review

\section{INTRODUCTION}

Psoriasis (PSO) and psoriatic arthritis (PsA) are autoimmune diseases that are highly relevant both clinically and economically. The overall prevalence of PSO ranges from 0.09 to $11.43 \%$, and PsA coexists with PSO in $1.3-34.7 \%$ of these patients [1]. In Spain, the prevalence of PSO stands at $2.31 \%$. This figure has increased over the last decade [2] and is higher in men than in women $(2.7 \%$ and $1.9 \%$, respectively). It is estimated that $7 \%$ of PSO patients in Spain could develop PsA, which would equate to approximately $0.2 \%$ of the PSO patient population [3].

Not only do these pathologies have a significant impact on the quality of lives of these patients, even when only a small area of the body is affected, but they also represent a significant cost to health services [1]. In Europe in particular, the annualized cost of PSO and PsA may reach international USD 13,132 and USD 17,050, respectively (USD-purchasing power parity [PPP] 2015, hypothetical currency that makes it possible to compare the purchasing power of different currencies; in this case, the Euro with the USD) [4].

Biological therapies (BT) are a well-established alternative for the treatment of immunemediated skin diseases [5]. The biological agent etanercept (ETN) is indicated in patients with PSO for whom another systemic therapy is contraindicated and for those who have not responded to or do not tolerate another systemic therapy, as well as in patients with active and progressive PsA, when the response to a previous disease-modifying antirheumatic drug treatment was inadequate [6].

Although ETN is frequently used in the clinical setting in Spain to treat PSO and PsA $[7,8]$, evidence of the economic impact of its use in the treatment of these immune-mediated diseases is limited. We have therefore performed a critical and systematic review and analysis of the relevant literature in order to draw conclusions on the decision-making process regarding available economic evaluations of the use of ETN to treat PSO and PsA in Spain.

\section{METHODS}

\section{Identification}

We performed a systematic review of citations in the PubMed, Medline and Embase Ovid databases up to November 2018. The search strategy was structured around recommendations for the performance of systematic reviews in economic evaluations [9], with the key concepts taken into account being population (PSO and PsA patients in Spain), intervention (ETN) and outcomes (economic evaluation/burden of disease). Studies with interventions but no comparator drug were also eligible for inclusion in the review. Subsequently, search terms related to the objective of the study were used (MeSH and free-text, Boolean operators for the performance of simple and combined searches). No restrictions were applied for the year of publication, type of study or language.

In order to identify the maximum number of references possible, the search was extended to the Cochrane Library, MEDES databases in Spanish, National Health Technology Assessment Agencies and journals of interest. A manual search was also conducted on abstracts and posters in communications presented to national and international congresses related to the area of interest that had been published between 2010 and 2018, namely, the American Academy of Dermatology (AAD), the Spanish Academy of Dermatology and Venereology (AEDV), the American College of Rheumatology (ACR), the European Academy of Dermatology and Venereology (EADV), the Spanish Health Economics Association (AES), the European Association of Hospital Pharmacists (EAHP), the European League Against Rheumatism (EULAR), the International Society for Pharmacoeconomics and Outcomes Research (ISPOR), the 
Spanish Society of Rheumatology (SER) and the Spanish Society of Hospital Pharmacy (SEFH).

\section{Study Selection}

Inclusion criteria were applied to language (publications in English and Spanish only), the country where the analysis was performed (Spain only), pathologies (PSO and PsA) and the type of study (economic evaluations). Publications that were not related to ETN or to the pathologies defined by the study, those that were not developed and conducted in Spain and those that were not economic evaluations (e.g. cost-effectiveness, cost-benefit, cost analysis, cost-consequence and cost-minimization studies) were excluded from the analysis. If there were two publications on the same study, both were selected, and they were jointly presented in the analysis of outcomes obtained.

PRISMA declaration criteria were applied to the identification process for duplicated, rejected and selected references [10].

\section{Data Extraction}

A tool was designed to facilitate the process of extracting data exclusively pertaining to ETN for all references published, with the following parameters: pathology, author-year, type of publication, type of economic evaluation, study characteristics, perspective, time horizon, type of costs, measures of effectiveness used and outcomes.

Each complete economic evaluation grouped studies evaluating at least two different alternatives and containing incremental cost data relating to a pre-determined effectiveness variable (e.g. responding patient PASI 75 [75\% reduction in the Psoriasis Area and Severity Index] at 12 weeks). Each partial economic evaluation included studies containing cost data for ETN, but the increase in costs was not assessed relative to another alternative with respect to a pre-determined effectiveness variable (e.g. cost analysis studies). In addition, costs studies evaluating the economic impact of the optimization of ETN doses (dose escalation, reduction or spacing) or of switching to biosimilar drugs were grouped and analyzed separately.

\section{Compliance with Ethics Guidelines}

This article is based on previously conducted studies and does not contain any studies with human participants or animals performed by any of the authors.

\section{RESULTS}

A total of 402 publications were identified, of which 32 were selected for data extraction (26 on PSO and 6 on PsA); of these latter 32 publications, $53.1 \%(n=17)$ were communications to congresses. Of the publications selected, 14 were classified as complete economic evaluations (cost-effectiveness or cost-benefit analysis) in patients with moderate-severe PSO, 18.8\% (5 on PSO and 1 on PsA) were classified as partial economic evaluations (cost and cost-minimization analyses) and $37.5 \%$ (6 on PSO and 5 on PsA) were classified as dose-optimization studies (Fig. 1).

\section{Study Characteristics}

\section{Complete Economic Evaluations}

Decision tree modeling was applied in 50\% $(n=7)$ of the complete economic evaluations, with a time horizon of between 12 weeks and 2 years [11-17]. With the exception of a solitary publication which included evaluations of the direct non-healthcare costs and the indirect costs owing to productivity loss [18], the Spanish National Health Service's (NHS) was the perspective mainly used. The main measures of effectiveness used were the percentage of patients obtaining a 50,75 or $90 \%$ improvement with respect to the baseline PASI score (PASI 50, 75 and 90, respectively), quality-adjusted life years (QALY) [19], the percentage of patients who were successfully treated (ETN maintained from the start) after 1 year [13] or the number needed to treat (NNT) [20]. The incremental efficacy results were extracted from pivotal clinical trials of ETN versus placebo [11, 14, 17-19, 21], evidence generated in Spain in a real-life clinical context [22-24] or results taken from previous meta-analyses [25, 26] (Electronic Supplementary Material [SEM] Table S1). 


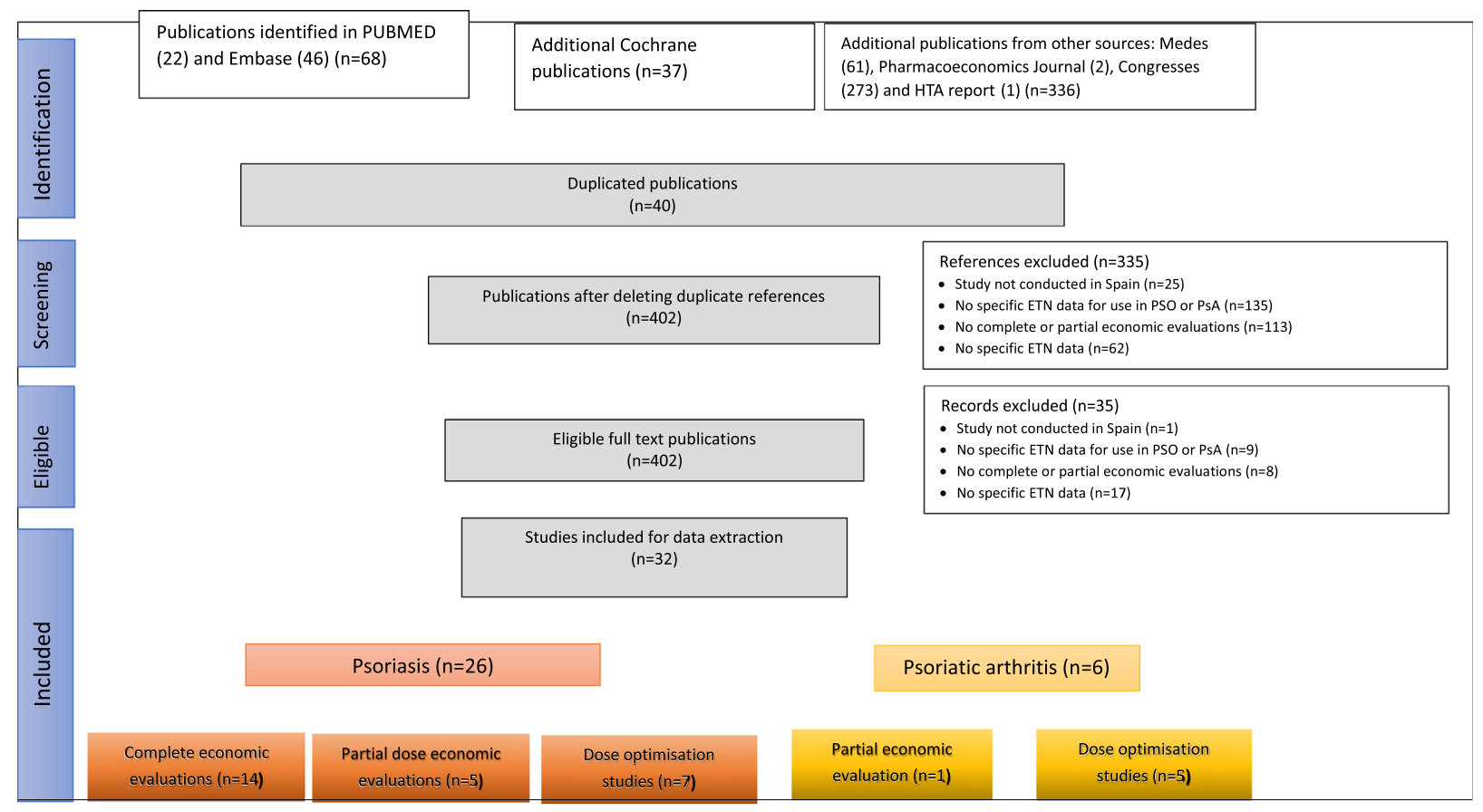

Fig. 1 Flow diagram of the publication selection process based on the PRISMA criteria [10]. ETN Etanercept, $H T A$ health technology assessment, Ps $A$ psoriatic arthritis, PSO psoriasis

\section{Partial Economic Evaluations}

Of the partial economic evaluations for moderate-severe PSO, four $(n=505$ patients treated with ETN) were based on observational studies in a real-life clinical context [27-30], and one study used modeling techniques [31]. All of the studies adopted the perspective of the NHS (only pharmacological costs), with the exception of one cost-minimization study which also considered indirect costs owing to loss of productivity [28]. The most commonly administered ETN regimen was $50 \mathrm{mg} /$ week, followed by a regimen of $2 \times 25 \mathrm{mg} /$ week or $2 \times 50 \mathrm{mg} /$ week.

We identified only one cost-analysis study that assessed-from the perspective of the NHS - the economic impact of ETN in patients with PsA ( $n=29$ patients treated with ETN) over the course of 1 year [8] (ESM Table S2).

\section{Dose Optimization}

The dose-optimization studies in real-life clinical contexts included in our systematic review evaluated the different types of interventions, including dose reduction $(n=4)$ [32-35], implementation of optimization protocols $(n=4)$ [36-39], dose spacing $(n=1)$ [40], optimization/escalation strategies $(n=1)$ [41], inclusion of multi-disciplinary committees $(n=1)$ [42] and switching to a biosimilar $(n=1)$ [43]. The PSO studies [32, 33, 36, 37, 40, 41, 43] all included the pharmacological costs with a time horizon of 1 year, with one exception, namely, a solitary study that used a horizon of 4 years and failed to specify the type of cost included in the analysis [36]. All PsA studies $(n=5)[34,35,38,39,42]$ used the perspective of the NHS, with a time horizon of between 6 months and 7 years (ESM Table S3).

\section{Results of Economic Evaluations}

\section{Complete Economic Evaluations}

A PASI 75 score is considered to be a reasonably satisfactory clinical outcome in the assessment of PSO. Using this criterion, our analysis of data from the original studies showed that the economic impact of ETN during the maintenance and induction phases was $€ 9110-9370$ for those 
with PASI 75 response rates at 12 weeks $(50 \mathrm{mg} /$ week) during the maintenance phase and $€ 12,797$ for those with PASI 75 response rates at 12 weeks $(2 \times 50 \mathrm{mg} /$ week $)$ during the induction phase $[11,12]$, with the annual cost increasing to $€ 23,034$ for those with PASI 75 response rates [22]. Other results found were $€ 20,178$ /year per patient treated successfully [13]. The impact of ETN when considering a PASI 90 response rate over 2 years as an outcome measure was $€ 89,279$. Analysis of the sequence of treatments of ETN with other BTs revealed an impact of $€ 45,672-71,558$ for PASI 90 response rates after 2 years when ETN therapy was combined with secukinumab and adalimumab, respectively [16] (Table 1 ).

A broad range of different clinical outcomes was also found in the selected conference abstracts. The cost-effectiveness using PASI 75 as the clinical outcome over a 1-year time horizon showed an inferior cost-effectiveness ratio $(€ 17,436 /$ PASI 75 at 1 year [14]). Another conference abstract also provided the cost per responder using this clinical outcome, although the time horizon was not specified ( $€ 8710 /$ responder PASI 75) [17]. ETN's NNT cost for the first year of treatment $(2 \times 50 \mathrm{mg} /$ week for 12 weeks followed by $50 \mathrm{mg} /$ week) ranged from $€ 29,277 / \mathrm{NNT}$ (PASI 75) to $€ 226,080 / \mathrm{NNT}$ (PASI 100 ), and from $€ 23,787 / \mathrm{NNT}$ (PASI 75 ) to $€ 183,690 / \mathrm{NNT}$ (PASI 100) in consecutive years (50 mg/week) [20]. Finally, the only cost-utility study yielded an incremental cost-utility ratio (expresses the correlation between incremental costs and QALYs) of $€ 29,430 / \mathrm{QALY}$ gained (ETN $2 \times 25 \mathrm{mg} /$ week) and $€ 52,367 /$ QALY gained (ETN 50 mg/week) [19] (Table 1).

\section{Partial Economic Evaluations}

The annual cost per patient with moderate-severe PSO who was treated with ETN ranged from $€ 4986$ (maintenance phase cost in patients receiving intermittent treatment) to $€ 12,327 /$ patient-year (maintenance phase cost in patients receiving continuos treatment) [30]. For patients who experienced loss of response to the ETN treatment, the annual escalation cost owing to dose duplication ranged from $€ 14,580$ (12-week intensification) to $€ 18,908$ (31-week intensification)/patient-year [31] (Table 2).
Data extracted from conference abstracts provided a total annual costs for PSO of $€ 15,268 /$ patient-year (year in which the treatment was started) [27] and the only cost analysis data conducted for PsA (using the NHS perspective), which yielded a cost result of $€ 8585$ /patient-year [8] (Table 2).

\section{Dose Optimization}

The total annual cost of a reduced ETN regime for the treatment of PSO varied from $€ 4160$ (50 mg/2 weeks) to $€ 8320 /$ patient-year $(25 \mathrm{mg} /$ week), whereas the escalated regime increased the annual cost up to $€ 23,773 /$ patient-year [32]. Dose optimization procedures for ETN doses in the treatment of PSO through the implementaion of optimization/escalation strategies and protocols resulted in a saving of $€ 859 /$ patientyear [37] (Table 3).

Conference abstracts showed savings of $€ 2012 /$ patient in 2 years of ETN use to treat PSO by increasing the dosing interval after protocol implementation [36]. Dose spacing in all patients treated with ETN also produced savings of $€ 15,216 /$ year, although this strategy represented only $13 \%$ of the total saving caused by dose spacing in BTs (adalimumab 69\%; infliximab 10\%, ustekinumab 8\%) [40]. Further, one study found an increase in treatment cost (difference between the theoretical value and the real value) of $€ 4754 /$ patient-year, owing primarily to the increased number of patients undergoing dose escalation [41].. The only study on switching to biosimilar drugs to treat PSO (reference value of $50 \mathrm{mg} / \mathrm{ml}$ ETN vs. biosimilar) yielded an annual saving of $18.7 \%$ (€6766.20 monthly saving) [43] (Table 3).

For PsA, a dose regime strategy led to a total saving of $€ 81,949$ over 7 years after the dose was changed from 50 to $25 \mathrm{mg} /$ week [38]. When our analysis was limited to results from conference abstracts, the protocol implementation entailed a saving of $€ 793-823 /$ patient-year $(€ 11,480 /$ patient-year before protocol implementation compared to $€ 10,657-10,687 /$ patient-year after protocol implementation) [34, 39], Further, lengthening of the dose interval (from weekly administration to a 10-day administration) produced an annual saving of $€ 1434 /$ patient [35] (Table 3). 


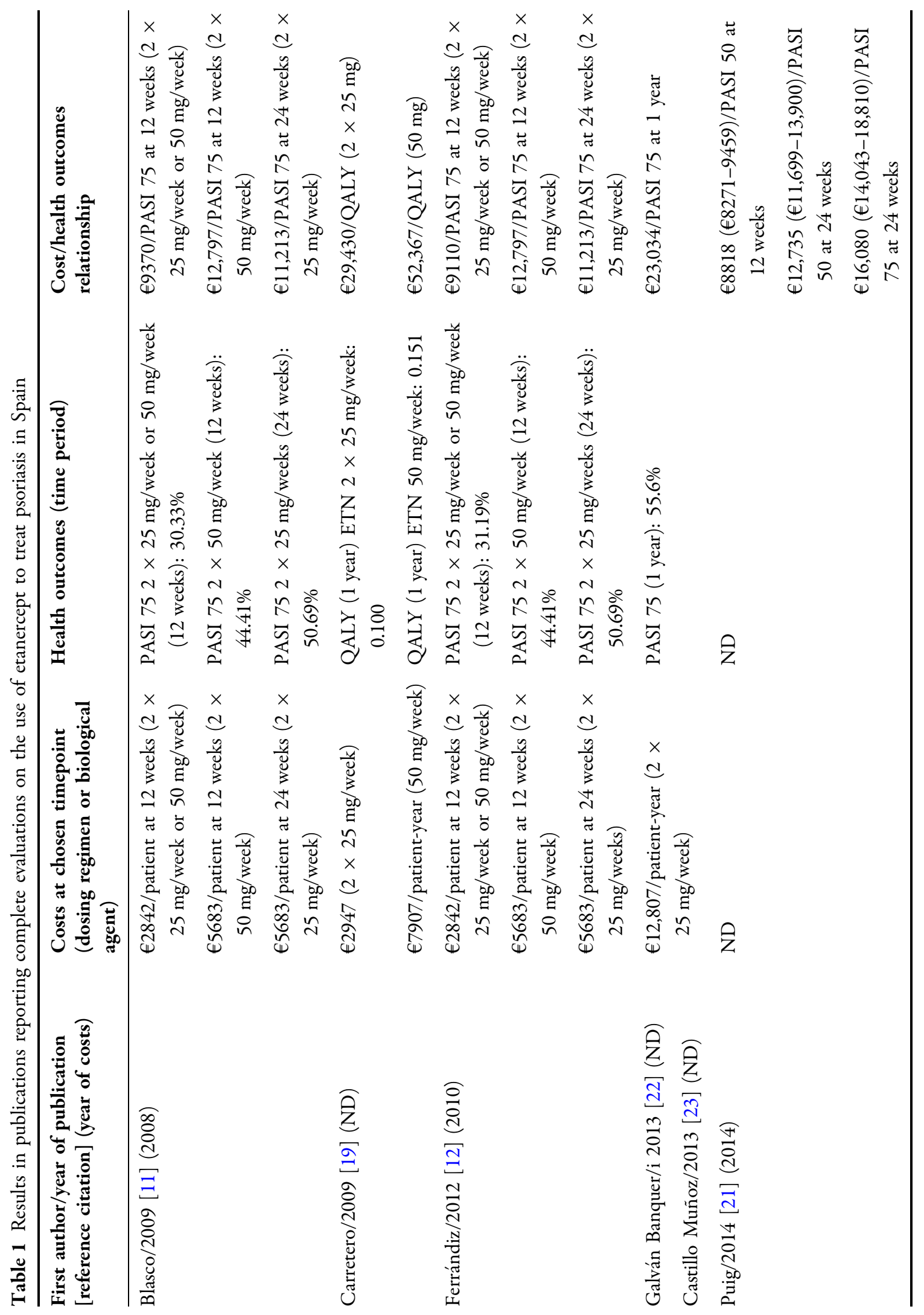




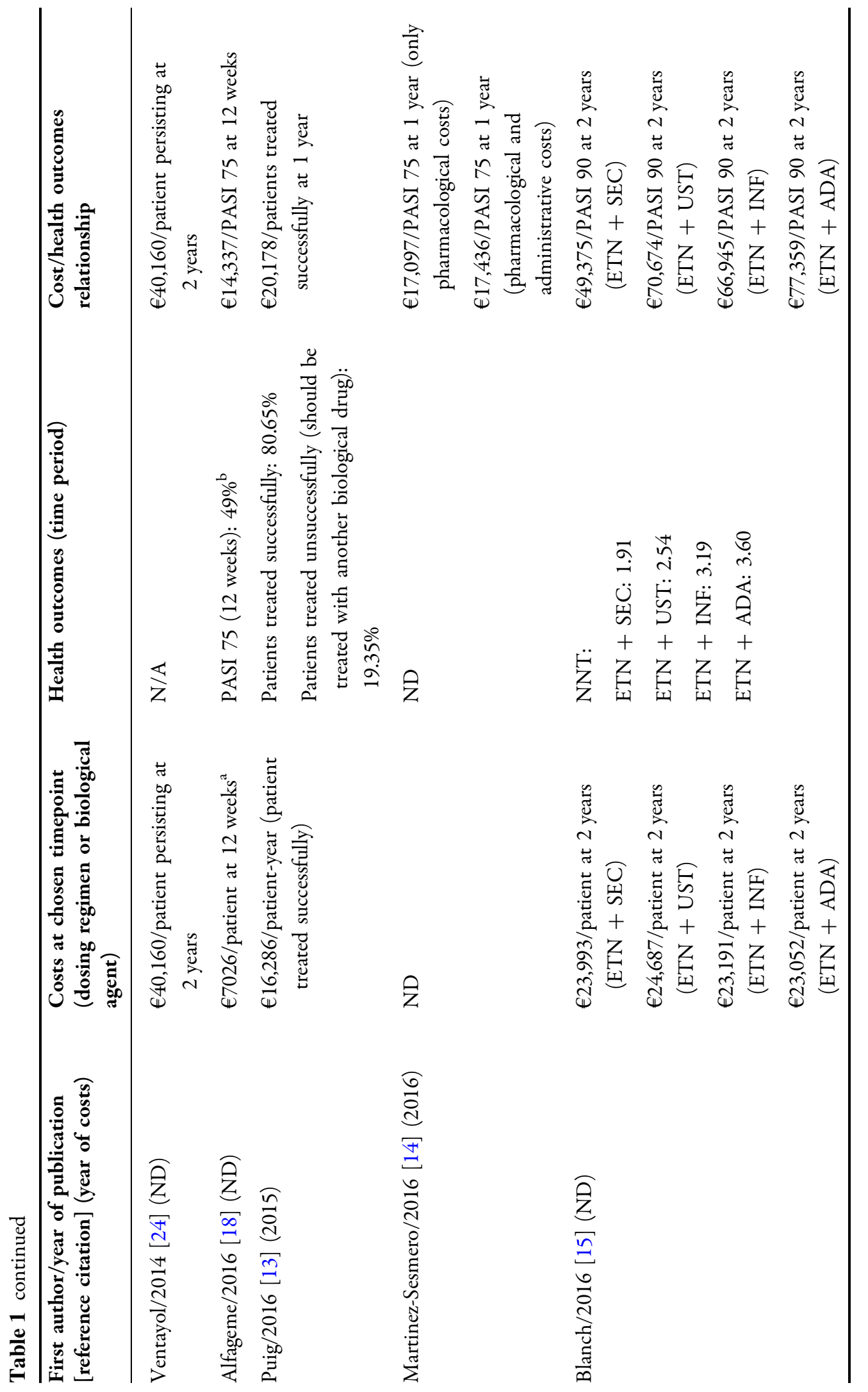




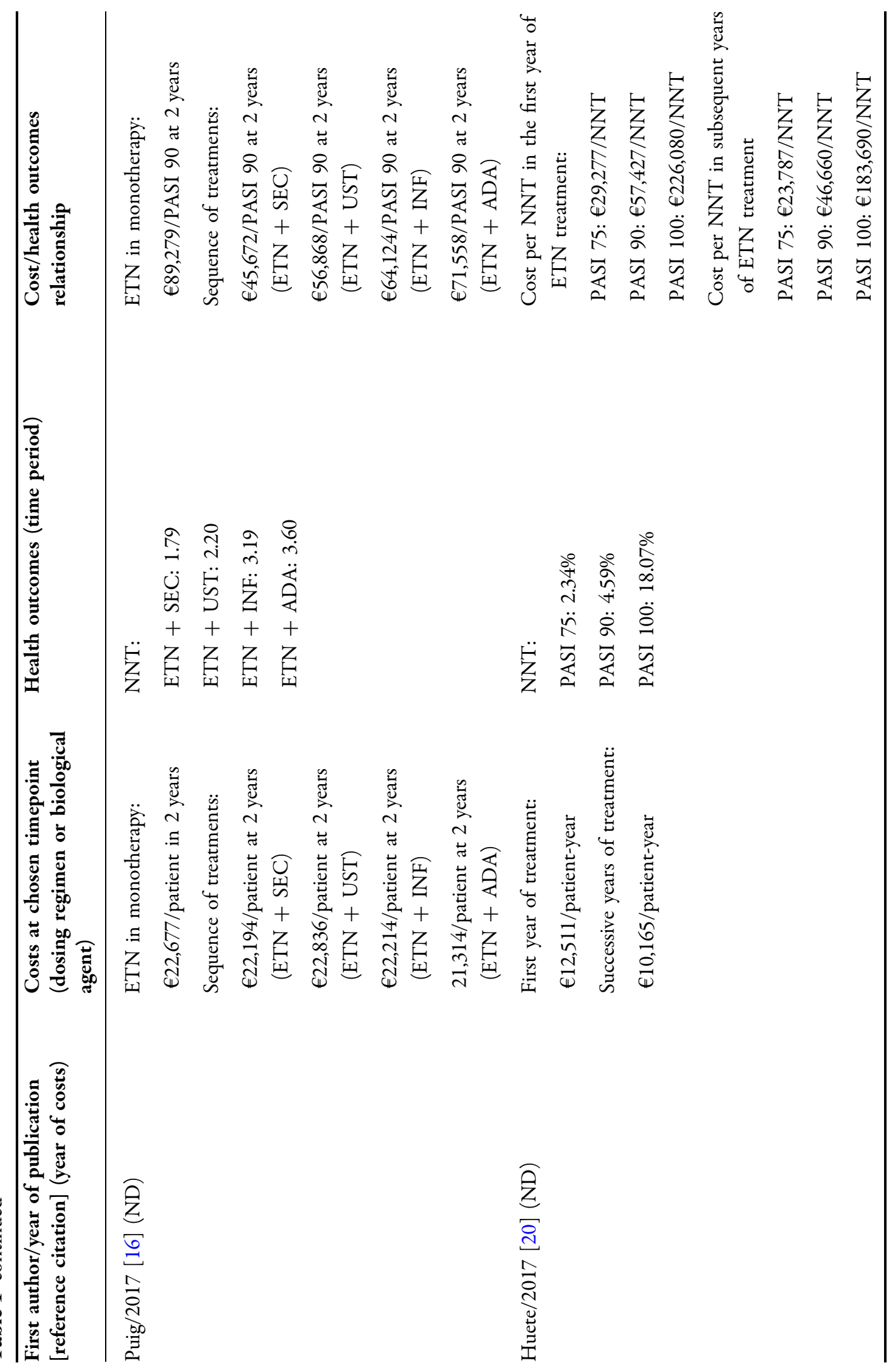




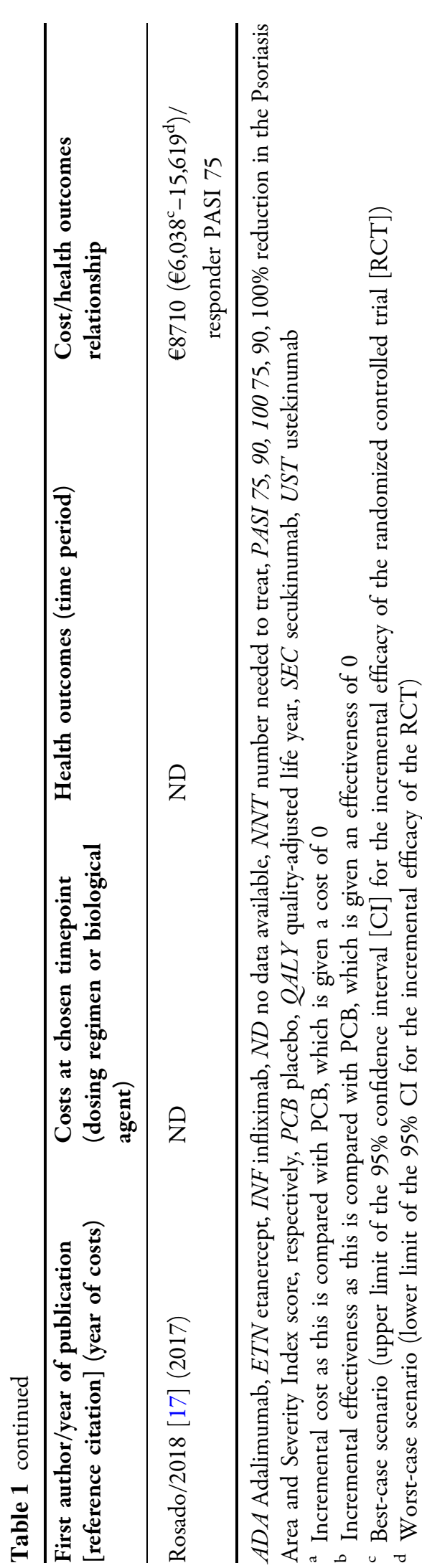

\section{DISCUSSION}

In our systematic review the distribution of publications according to pathology was asymmetrical, with the majority focusing on PSO $(81.3 \%$ [PSO] vs. $18.8 \%$ [PsA]). Of the publications identified, $43.8 \%$ were complete economic evaluations. The majority of these complete economic evaluations were models based on the results of pivotal clinical trials or prior meta-analyses, with three studies using data in a real clinical context to obtain an incremental cost-effectiveness ratio [22-24]. Although the main measure of effectiveness was the PASI 75 response at 12 and 24 weeks $[11,12,18,21]$ (the end of the induction phase and the time of assessment of the clinical response to PSO treatment, respectively), a wide range of incremental efficacy measurements were also used (PASI 50, PASI 90, PASI 100, QALY, NNT, patients successfully treated, persisting patients) in addition to various ETN administration regimens $(2 \times$ $25 \mathrm{mg} /$ week, $2 \times 50 \mathrm{mg} /$ week, $50 \mathrm{mg} /$ week)—in some studies not always specified [14-16, 24]and time horizons (ranging from 12 weeks to 2 years). The NHS perspective was adopted in the majority of studies (there was only one total economic evaluation that included indirect costs) and was restricted almost exclusively to pharmacological costs. The cost of induction in Spain was $€ 9110-9370$ and $€ 12,797$ per PASI 75 responder at 12 weeks at $2 \times 25 \mathrm{mg}$ and $2 \times 50 \mathrm{mg}$ weekly doses, respectively $[11,12]$, and $€ 11,213-16,080$ per PASI 75 responder at 24 weeks $[11,12,21]$ (even though the studies of Blasco et al. [11] and Ferrandiz et al. [12] differ, both sets of authors reported practically identical results). A study by Alfageme et al. [18] yielded a cost of $€ 14,337$ per PASI 75 responder at 12 weeks (doses not detailed).

Other studies reported the annual cost of reaching PASI 75 or for achieving "therapeutic success" per patient-PASI 75 (€23,034/PASI 75 at 1 year to $€ 20,178$ /patient treated successfully at 1 year) $[13,22,23]$, but these results were difficult to group with others due to methodological differences, as was the the case with results for PASI 90 patients at 2 years who also used biological drug treatment sequences $[15,16]$. The only ETN costbenefit analysis presented an incremental cost-benefit ratio for the $2 \times 25 \mathrm{mg} /$ week regimen 
Table 2 Results of the partial economic evaluations on the use of etanercept to treat psoriasis and psoriatic arthritis in Spain

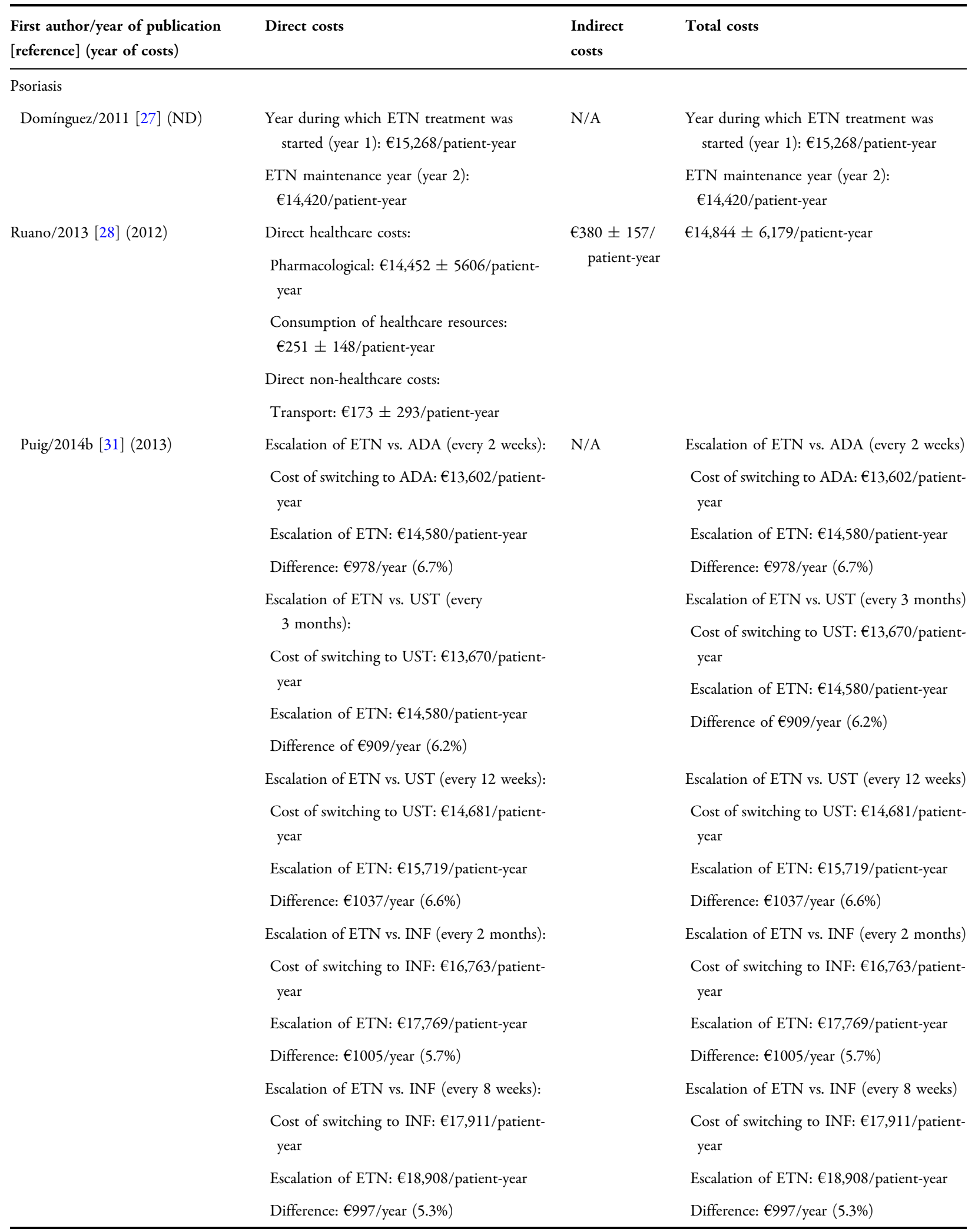


Table 2 continued

\begin{tabular}{lllc}
\hline $\begin{array}{l}\text { First author/year of publication } \\
\text { [reference] (year of costs) }\end{array}$ & Direct costs & $\begin{array}{l}\text { Indirect } \\
\text { costs }\end{array}$ & Total costs \\
\hline Fernández-Torres/2015 [29] (ND) & $€ 244.60 \pm 45.20 /$ PASI 75 in 1 week & N/A & $€ 244.60 \pm 45.20 /$ patient-week \\
Ruiz-Villaverde/2016 [30] (ND) & $11,299(95 \%$ CI $€ 10,551-12,046) /$ patient- & N/A & $\begin{array}{c}11,299(95 \% \text { CI } € 10,551-12,046) / \text { patient- } \\
\text { year }\end{array}$ \\
& year & Continuous treatment: \\
& Continuous treatment: & Cost of the induction phase (year 1): \\
& $€ 12,294 /$ patient-year & $€ 12,294 /$ patient-year \\
& Cost of the maintenance phase (year 2): & Cost of the maintenance phase (year 2): \\
& $€ 12,327 /$ patient-year & $€ 12,327 /$ patient-year \\
& Intermittent treatment: & Intermittent treatment: \\
& Cost of the induction phase (year 1): & Cost of the induction phase (year 1): \\
& $€ 10,302 /$ patient-year & $€ 10,302 /$ patient-year
\end{tabular}

that was higher than those reported in Germany ( $€ 18,154 / \mathrm{QALY})$ [44] and Italy ( $€ 25,840 / \mathrm{QALY})$ [45], although this could be considered to be an efficient alternative conditioned to the cost-effectiveness thresholds routinely considered in Spain (€25,000-30,000/QALY) [46, 47].

Similar to the complete economic evaluations, the partial economic evaluations primarily focused on treatment of PSO, with only one evaluation (cost analysis) presenting economic impact data on treatment of PsA. The majority of these were observational studies with a time horizon of between 1 and 2 years and restricted to evaluations of the costs of ETN treatment. The perspective in all studies but one was that of the NHS [28], which contrasts with the perspective used in another review on the overall impact of these pathologies in Europe [4] in which the social perspective was primarily used. The annual cost per PSO patient receiving ETN treatment varied widely $(€ 4,986-€ 15,268 / \mathrm{pa}-$ tient-year) [27, 30], resulting in an annual cost of $€ 18,908 /$ patient if an extension of 31 weeks of escalated treatment is considered [31], suggesting that it may be higher than the overall cost of the pathology reported in Europe $(13,132$ USD-PPP) [4]. In contrast to the above, the annual cost per patient reported by the only publication on the use of ETN in the treatment of PsA in Spain is significantly lower than the referenced study (€8,585/patient-year vs. $€ 10,924-17,050$ USD-PPP/patient-year) [4].

A third analysis category, namely study type, includes publications on dose optimization (37.5\%), observational and cross-sectional studies with types of procedures (dose escalation, spacing and optimization protocols, switching to biosimilars) and highly heterogeneous cost measures (cost before and after protocol implementation, percentage of saving, actual or theoretical annual cost) that hinder the standardization of the results, although they do highlight the importance of these types of procedures for health professionals.

There are various limitations to our sytematic review which need to be taken into account when interpreting the results. First, given the exhaustiveness of the search strategy, a high proportion of communications to national and international congresses were included-a format which, given its limited extension, routinely includes little information on methodological aspects. This approach led us to not evaluate the quality of the publications 
Table 3 Results of the studies on modification of the dosing regimen used to treat psoriasis and psoriatic arthritis in Spain

\begin{tabular}{lll}
\hline $\begin{array}{l}\text { First author/year of } \\
\text { publication [reference] }\end{array}$ & Effectiveness results & Cost results \\
(year of costs) &
\end{tabular}

Psoriasis

Fernández-Espínola/ 2013/ [36] (ND)
Variation of average treatment rest time after protocol vs. before protocol: 8.5 weeks

Before protocol

Baseline PASI: NR

Time until reaching PASI 75: NR

Time until disease remission:

22.5 weeks (SD 8.8)

Number of restarts per patient: 1.8

(SD 0.6)

After protocol

Baseline PASI: 23.2 (SD 10.1)

Time until reaching PASI 75:

30.4 weeks

Time until disease remission:

31 weeks (SD 15 weeks)

Number of restarts per patient: 2.6

(0.7)

Baniandres/2015 [32] (2014)
Average dose reduction/patient-year: $13.8 \%$

Patient with standard regimen: $54 \%$

Dose reduction of standard regimen $(2 \times 25 \mathrm{mg} /$ week $)$ to:

$25 \mathrm{mg} /$ week: $4.2 \%$

$25 \mathrm{mg} / 10$ days: $8.3 \%$

$50 \mathrm{mg} / 10$ days: $20.8 \%$

$50 \mathrm{mg} / 2$ weeks: $8.3 \%$

Dose escalation to $100 \mathrm{mg} /$ week over a period of longer than 12 weeks: $4.2 \%$
Estimated potential saving due to increasing the dosing interval (more rest) after protocol implementation over 2 years: €2012/patient in 2 years
Saving of ETN (\%): 13.8 (total expenditure: $€ 246,046)$

Average actual cost for ETN, taking into account all modifications (standard, reduction and escalation): $€ 10,252 /$ patient-year

Actual annual cost of the standard ETN regimen: $€ 11,886 /$ patient-year

Actual annual cost of the reduced ETN regimen: 25 mg/week: €8320/patient-year

$25 \mathrm{mg} / 10$ days: $€ 5943 /$ patient-year $50 \mathrm{mg} / 10$ days: $€ 5943 /$ patient-year 50 mg/2 weeks: $€ 4160 /$ patient-year Actual annual cost of escalated ETN regimen: $€ 23,773 /$ patient-year 
Table 3 continued

\begin{tabular}{|c|c|c|}
\hline $\begin{array}{l}\text { First author/year of } \\
\text { publication [reference] } \\
\text { (year of costs) }\end{array}$ & Effectiveness results & Cost results \\
\hline $\begin{array}{l}\text { Romero-Jiménez/2015 } \\
{[40](\mathrm{ND})}\end{array}$ & $\begin{array}{l}\text { Dose spacing in patients receiving } \\
\text { ETN treatment: } 37.5 \% \\
\text { Doses used vs. doses on the ETN } \\
\text { SPC: } 92.8 \%\end{array}$ & $\begin{array}{l}\text { Annual saving after protocol implementation with } \\
\text { ETN: } € 15,216 / \text { year }\end{array}$ \\
\hline $\begin{array}{l}\text { Ríos-Sanchez/2015 [33] } \\
\text { (ND) }\end{array}$ & $\%$ patients with PASI $75: 90 \%$ & $\begin{array}{l}\text { Actual cost: } € 10,389 / \text { patient-year } \\
\text { Estimated theoretical cost (theoretical prescribed } \\
\text { doses): } € 11,576 / \text { patient-year } \\
\text { Estimated actual cost (actual prescribed doses): } \\
€ 9445 / \text { patient-year }\end{array}$ \\
\hline \multirow[t]{4}{*}{$\begin{array}{l}\text { Romero-Jiménez/2016 } \\
\text { [37] (2014) }\end{array}$} & $\begin{array}{l}\% \text { patients with dose reduction } \\
\text { (increased administration interval): } \\
37.5 \%\end{array}$ & $\begin{array}{l}\text { Pre-protocol period } \\
\text { Actual cost of the pre-protocol period/patient-year } \\
(95 \% \text { CI }) € 11,661(€ 9702-13,620) / \text { patient-year }\end{array}$ \\
\hline & $\begin{array}{l}\text { Pre-protocol period } \\
\% \text { patients who reached PASI } 75: \\
60 \%\end{array}$ & $\begin{array}{l}\text { Saving corresponding to the pre-protocol period } \\
\text { (actual dose vs. standard dose) }(95 \% \text { CI) } € 225 \text { (€- } \\
1734-2184) \text { patient-year }{ }^{a}\end{array}$ \\
\hline & $\begin{array}{l}\text { \% standard dose used }(95 \% \text { CI }) 98.1 \\
(79.8-116.4) \\
\text { Post-protocol period }\end{array}$ & $\begin{array}{l}\text { Post-protocol period } \\
\text { Actual cost of the post-protocol period }(95 \% \mathrm{CI}) \\
€ 11,028(€ 8951.60-13,104.40) / \text { patient-vear }\end{array}$ \\
\hline & $\begin{array}{l}\text { \% patients who reached PASI 75: } \\
63 \% \\
\% \text { standard dose used }(95 \% \text { CI) } 92.8 \\
(77.1-108.6)\end{array}$ & $\begin{array}{l}\text { Saving corresponding to the post-protocol period } \\
\text { (actual dose vs standard dose) (95\% CI) €859 (€- } \\
1217-2935.40) / \text { patient-year }\end{array}$ \\
\hline $\begin{array}{l}\text { Corregidor/2016 [41] } \\
\text { (ND) }\end{array}$ & $\begin{array}{l}\% \text { patients receiving standard regimen } \\
\text { of ETN ( } 50 \mathrm{mg} / \text { week): } 51.1 \% \\
\% \text { patients receiving optimized } \\
\text { regimen: } 6.2 \% \\
\% \text { patients receiving the escalated } \\
\text { regimen }(100 \mathrm{mg} / \text { week): } 42.7 \%\end{array}$ & $\begin{array}{l}\text { Difference between the actual overall cost and the } \\
\text { theoretical overall cost: } € 99,832 / \text { year (representing } \\
\text { an increase of } € 4754 / \text { patient-year for ETN) }\end{array}$ \\
\hline $\begin{array}{l}\text { Rosado/2017/) [43] } \\
(\text { ND) }\end{array}$ & $\begin{array}{l}\text { Same PASI level as before switching } \\
\text { to biosimilar } \\
\text { No adverse effect was recorded } \\
\text { during the process }\end{array}$ & $\begin{array}{l}\text { Monthly saving of } € 6766.20 \text { (percentage saving: } \\
18.7 \% \text { ) }\end{array}$ \\
\hline
\end{tabular}


Table 3 continued

\begin{tabular}{|c|c|c|}
\hline $\begin{array}{l}\text { First author/year of } \\
\text { publication [reference] } \\
\text { (year of costs) }\end{array}$ & Effectiveness results & Cost results \\
\hline \multicolumn{3}{|l|}{ Psoriatic arthritis } \\
\hline $\begin{array}{l}\text { Borras-Blasco/2014 [36] } \\
(2012)\end{array}$ & $\begin{array}{l}\text { Average time receiving treatment } \\
\text { with ETN } 25 \mathrm{mg} / \text { week: } 0.9 \pm 0.2 \\
\text { DAS } 28 / \text { BASDAI } \\
\text { Baseline (ETN } 50 \mathrm{mg} / \text { week): } \\
2.4 \pm 1.2 \\
\text { Start of regimen } 25 \mathrm{mg} / \text { week: } \\
1.7 \pm 0.4 \\
\text { Regimen } 25 \mathrm{mg} / \text { week } \geq 6 \text { months: } \\
2.1 \pm 0.4\end{array}$ & $\begin{array}{l}\text { Total saving made by switching ETN } 50 \mathrm{mg} / \text { week to } \\
\text { ETN } 25 \mathrm{mg} \text { /week ( } 7 \text { years): } € 81,949 \text { in } 7 \text { years. }\end{array}$ \\
\hline $\begin{array}{l}\text { Borras-Blasco/2014a [34] } \\
\text { (ND) }\end{array}$ & NR & $\begin{array}{l}\text { Cost corresponding to the pre-protocol period: } \\
€ 11,480 / \text { patient-year }\end{array}$ \\
\hline $\begin{array}{l}\text { Borras-Blasco/2014b [39] } \\
\text { (ND) }\end{array}$ & & $\begin{array}{l}\text { Cost corresponding to the post-protocol period: } \\
€ 10,687 / \text { patient-year }(€ 10,657 / \text { patient-year for } \\
\text { Borrás-Blasco et al. [36]) }\end{array}$ \\
\hline Rentero/2016 [42] (ND) & NR & $\begin{array}{l}\text { Intervention period: } € 883.82 \text { per patient in } 6 \text { months } \\
\text { Pre-intervention period: } € 824.74 \text { per patient in } \\
6 \text { months }\end{array}$ \\
\hline $\begin{array}{l}\text { Prada-Ojeda/016 [35] } \\
\text { (ND) }\end{array}$ & NR & $\begin{array}{l}\text { Saving entailed by switching from the standard } \\
\text { regimen procedure to: } \\
25 \mathrm{mg} / \text { week regimen: } € 3937.96 / \text { year } \\
25 \mathrm{mg} / 10 \text { days regimen: } € 2503.80 / \text { year }\end{array}$ \\
\hline
\end{tabular}

BASDAI Bath Ankylosing Spondylitis Disease Activity Index, DAS Disease activity Score, $N / A$ not applicable, $N R$ not reported, $S D$ standard deviation, NHS Spanish National Health Service, SPC summary of product characteristics

a Statistically significant differences between the pre-protocol period and the post-protocol period $(p<0.05)$

selected through a valid tool, such as the Consolidated Health Economic Evaluation Reporting Standards (CHEERS) [48]. Second, the cost outcomes obtained were not updated to 2019 values $(€, 2019)$, thus hindering comparability with other results. However, given the diversity of the incremental efficacy variables and the time horizons used (patient-year, patient/PASI 75 at 12 weeks, QALY) in the selected studies, it is difficult to unify the results. Third, the heterogeneity of this review is assumed, given that two pathologies (PSO and PsA) and the different ETN treatment regimens have been reviewed, as well as the different outcome measurements, in an attempt to succinctly collect all available information.

\section{CONCLUSION}

To conclude, the economic evaluations conducted in Spain on the use of ETN to treat PSO and PsA should be framed within the context of high heterogeneity, mainly due to substantial 
differences in the design of the studies performed to date (e.g. different dosing regimens, different efficacy measurements, different time horizons, etc.), yielding a wide range of costs and leading to a lack of consistent evidence.

\section{ACKNOWLEDGEMENTS}

Funding. Pfizer S.L.U. has unconditionally financed the execution of this project and the journal's article processing charges. All authors had full access to the articles reviewed in this manuscript and take complete responsibility for the integrity and accuracy of this manuscript.

Authorship. All named authors meet the International Committee of Medical Journal Editors (ICMJE) criteria for authorship for this article, take responsibility for the integrity of the work as a whole, and have given their approval for this version to be published.

Authorship Contributions. All authors have had access to the data and have contributed to the conceptualisation and writing of the manuscript. All of the above authors declare that they have made substantial contributions and have reviewed the final manuscript. FJRL is the guarantor of the general content in this manuscript.

Disclosures. Ismael Gomez works at Pfizer. Susana Gomez works at Pfizer. Carmen Peral works at Pfizer. Francisco José Rebollo Laserna works at Pfizer. Ramón de Burgos Pol works at PORIB, which has received unconditional funding from Pfizer for the writing of this manuscript. Lluis Puig has been paid by Pfizer for his collaboration and consultancy in the writing of this manuscript. Lourdes Rodríguez Fernández-Freire has been paid by Pfizer for her collaboration and consultancy in the writing of this manuscript.

Compliance with Ethics Guidelines. This article is based on previously conducted studies and does not contain any studies with human participants or animals performed by any of the authors.
Data Availability. All data generated or analyzed during this study are included in this published article/as supplementary information files.

Open Access. This article is distributed under the terms of the Creative Commons Attribution-NonCommercial 4.0 International License (http://creativecommons.org/licenses/ by-nc/4.0/), which permits any noncommercial use, distribution, and reproduction in any medium, provided you give appropriate credit to the original author(s) and the source, provide a link to the Creative Commons license, and indicate if changes were made.

\section{REFERENCES}

1. World Health Organization. Global report on Psoriasis. Ginebra: World Health Organization; 2016. http://apps.who.int/iris/bitstream/10665/204417/ 1/9789241565189_eng.pdf. Accessed 27 Oct 2017.

2. Ferrándiz C, Carrascosa JM, Toro M. Prevalencia de la Psoriasis en España en la era de los biológicos. Actas Dermosifiliogr. 2014;105(5):504-9.

3. López-Estebaranz JL, Zarco-Montejo P, EscalasTaberner J, García-Rodríguez M, García-Llorente JF, García-Calvo C. Manejo clínico de la artritis psoriásica en España: estudio Calipso. Actas Dermosifiliogr. 2010;101(7):629-36.

4. Burgos-Pol R, Martínez-Sesmero JM, Ventura-Cerdá JM, Elías I, Caloto MT, Casado MÁ. Coste de la Psoriasis y Artritis Psoriásica en cinco países de Europa: una revisión sistemática. Actas Dermosifiliogr. 2016;107(7):577-90.

5. Puig L, Carrascosa JM, Carretero G, et al. Spanish evidence-based guidelines on the treatment of Psoriasis with biologic agents, 2013. Part 1: on efficacy and choice of treatment. Spanish Psoriasis Group of the Spanish Academy of Dermatology and Venereology. Actas Dermosifiliogr. 2013;104(8): 694-700.

6. Agencia Española de Medicamentos y Productos Sanitarios. Ficha técnica de Enbrel. https://www. aemps.gob.es/cima/pdfs/es/ft/99126022/FT_ 99126022.pdf. Accessed 27 Oct 2017.

7. Hernánz JM, Sánchez-Regaña M, Izu R, Mendiola V, García-Calvo C. Evaluación clínica y terapéutica de los pacientes con psoriasis moderada o grave en 
España. Estudio Secuence. Actas Dermosifiliogr. 2012;103(10):897-904.

8. Acosta P, Gimeno MJ, Sanchez A, Tarín MJ, Fayet A. Cost analysis of self-injectable anti-TNF in Almeria (Spain)(OHP015). Eur J Hosp Pharm. 2012;19(2):205.

9. Thielen FW, Van Mastrigt G, Burgers LT, et al. How to prepare a systematic review of economic evaluations for clinical practice guidelines: database selection and search strategy development (part 2/3). Expert Rev Pharmacoecon Outcomes Res. 2016;16(6):705-21.

10. Moher D, Liberati A, Tetzlaff J, Altman DG, PRISMA Group. Preferred reporting items for systematic reviews and meta-analyses: The PRISMA statement. PLoS Med. 2009;6:e1000097.

11. Blasco AJ, Lázaro P, Ferrándiz C, García-Díez A, Liso J. Eficiencia de los agentes biológicos en el tratamiento de la psoriasis moderada-grave. Actas Dermosifiliogr. 2009;100(9):792-803.

12. Ferrándiz C, García A, Blasco AJ, Lázaro P. Cost-efficacy of adalimumab, etanercept, infliximab and ustekinumab for moderate-to-severe plaque Psoriasis. J Eur Acad Dermatol Venereol. 2012;26(6):768-77.

13. Puig L, López-Ferrer A, Vilarrasa E, García I, Fernández-del Olmo R. Modelo de eficiencia de los fármacos biológicos en el tratamiento de la Psoriasis moderada-grave durante un año en las condiciones de uso en España. Actas Dermosifiliogr. 2016;107(1):34-43.

14. Martinez-Sesmero M, Schoendorff C, Caloto T. Cost per responder of apremilast versus infliximab biosimilar, etanercept, adalimumab, ustekinumab and SEC in patients with moderate to severe psoriasis in Spain. Value Health. 2016;19(7):A569.

15. Blanch C, Prades M, Lizan L, Figueras M. Uso de fármacos biológicos para el tratamiento de la Psoriasis moderada-grave. Eficacia máxima y eficiencia no son incompatibles. In: Comunicaciones 36th Jornadas de Economía de la Salud (AES); 15-16 June. Murcia, Spain: AES; 2016. p. 118.

16. Puig L, Notario J, Jiménez-Morales A, et al. Secukinumab is the most efficient treatment for achieving clear skin in psoriatic patients: a costconsequence study from the Spanish National Health Service. J Dermatolog Treat. 2017;28(7):623-30.

17. Rosado AA, Román AF, Muñoz NH, et al. A costeffectiveness analysis of biological therapies for moderate to severe psoriasis. Eur J. Hosp Pharm. 2018;25:A8-9.
18. Alfageme Roldán F, Bermejo Hernando A, Calvo González JL, Marqués Sánchez P. Coste efectividad para diferentes tratamientos para la psoriasis. Rev Esp Salud Publica. 2016;13(90):E15.

19. Carretero G, Moreno JC, Notario J, et al. Cost-effectiveness of biologic treatments for moderate to severe psoriasis (PSS25). Value in Health. 2009;12(7):A457.

20. Huete T, Núñez M, Sacristán JA, Hartz S, Dilla T. Evaluación de la eficiencia de los tratamientos biológicos para la psoriasis moderada a grave en España: análisis de coste por NNT. In: 45 Congreso Nacional de Dermoatología y Venerología (AEDV). Madrid: AEDV; 2017, p. 87.

21. Puig L, López-Ferrer A, Vilarrasa E. Análisis de costeeficacia incremental de los tratamientos biológicos para la psoriasis en los momentos de valoración significativos para la práctica clínica. Actas Dermosifiliogr. 2014;105(10):951-3.

22. Galván-Banqueri M, Castillo-Muñoz MA, BeltránCalvo C, Molina-López T. Tratamiento con agentes biológicos en pacientes adultos con psoriasis en placas moderada-grave. Sevilla: Agencia de Evaluación de Tecnología Sanitarias de Andalucía (AETSA);2013.

23. Castillo-Muñoz MA, Galván-Banqueri M, UbagoPérez R, Vega-Coca MD, Beltrán-Calvo C, MolinaLópez T. Eficiencia de las terapias biológicas en el tratamiento de la psoriasis en placa moderada-grave (652). Farm Hosp. 2013[Suppl 1]:65-499-309.

24. Ventayol P. Drug survival rates and cost of biological agents for the treatment of moderate to severe psoriasis in the Balearic Islands (Spain). Value Health. 2014;17(7):A610.

25. Puig L, López A, Vilarrasa E, García I. Efficacy of biologics in the treatment of moderate-to-severe plaque psoriasis: a systematic review and metaanalysis of randomized controlled trials with different time points. J Eur Acad Dermatol Venereol. 2014;28(12):1633-53.

26. Nast A, Jacobs A, Rosumeck S, Werner RN. Efficacy and safety of systemic long-term treatments for moderate-to-severe psoriasis: a systematic review and meta-analysis. J Invest Dermatol. 2015;135(11):2641-8.

27. Domínguez-Gil A, Moreno D, Garcia D, Campo C. Annual cost of biological therapies for the treatment of moderate to severe plaque psoriasis in Spain. Value Health. 2011;14(7):A505.

28. Ruano J, Isla-Tejera B, Jiménez-Puya R, et al. Longterm cost-effectiveness analysis of etanercept and adalimumab for plaque psoriasis not associated 
with arthritis. Dermatol Ther (Heidelb). 2013;3(2):131-42.

29. María Fernández-Torres R, Paradela S, Fonseca E. Long-term efficacy of etanercept for plaque-type psoriasis and estimated cost in daily clinical practice. Value Health. 2015;18(8):1158-61.

30. Ruiz-Villaverde R, Galán-Gutierrez M, BarabashNeila R, Rodriguez-Fernandez-Freire L, Conejo-Mir J. Efficacy and cost of etanercept in long-term psoriasis: rational use in clinical practice. J Dermatol Treat. 2016;27(1):37-42.

31. Puig L. Tratamiento de la psoriasis en placas moderada a grave con fármacos biológicos: análisis del sobrecoste de la intensificación temporal frente a cambio a otro biológico en caso de fracaso secundario. Actas Dermosifiliogr. 2014;105(4):401-12.

32. Baniandrés O, Rodríguez-Soria VJ, Romero-Jiménez RM, Suárez R. Modificación de la dosis de terapias biológicas en psoriasis moderada-grave: análisis descriptivo en condiciones de práctica clínica. Actas Dermosifiliogr. 2015;106(7):569-77.

33. Sanchez E, Fenix-Caballero S, de Gandara-Ladron Guevara M, Palomo-Palomo C, Diaz-Navarro J, Borrero-Rubio J, et al. Biological treatments for Psoriasis: financial impact of dose modification. Eur J Hosp Pharm. 2015;22[Suppl 1]:1-230.

34. Borrás Blasco J, Casterá DE, Abad FJ, Rosique Robles JD, Lázaro Perona C. Implementación de un protocolo de priorización de terapia biológica basado en criterios de coste-efectividad como herramienta para la mejora del empleo de fármacos biológicos en pacientes con artropatía psoriásica. Farm Hosp. 2014;38:115-6.

35. Prada Ojeda A, Sánchez-Largo Uceda ME, Esteva Jiménez L, Sala Icardo LG, del Ibañes Agua S, Calzado Villarreal L. Benefits of dose tapering strategies within the psoriatic arthritis multidisciplinary units [FRI0441]. Ann Rheum Dis. 2016;75[Suppl 2]:595.

36. Fernández Espínola S, Galán Retamal C, Garrido Fernández R, Padilla Marín V. Uso eficiente de terapia biológica en psoriasis placa moderada-severa (131). Farm Hosp. 2013;65-499.

37. Romero-Jimenez RM, Escudero-Vilaplana V, Baniandres Rodriguez O, Garcia-Gonzalez X, Sanjurjo Saez M. Efficiency of biological therapies in patients with moderate to severe psoriasis: impact of a pharmacotherapeutic protocol. J Dermatolog Treat. 2016;27(3):198-202.

38. Borrás-Blasco J, Gracia-Pérez A, Rosique-Robles JD, Casterá ME, Abad FJ. Clinical and economic impact of the use of etanercept $25 \mathrm{mg}$ once weekly in rheumatoid arthritis, psoriatic arthropathy and ankylosing spondylitis patients. Expert Opin Biol Ther. 2014;14(2):145-50.

39. Borras-Blasco J, Casterá DE, Abad FJ, Rosique-Robles JD. Management improvements associated with a biological therapy multidisciplinary commission in psoriatic arthropathy patients in the Hospital of Sagunto [AB0750]. Ann Rheum Dis. 2014;73[Suppl 2]:1052.

40. Romero-Jimenez RM, Escudero-Vilaplana V, Baniandres Rodriguez O, Tovar-Pozo M, Ais-Larisgoitia A, Sanjurjo Saez M. Impacto de un protocolo de utilización eficiente de terapias biológicas en pacientes con psoriasis moderada-grave. In: Comunicaciones 60 congreso de la Sociedad Española de Farmacia Hospitalaria (SEFH). Valencia, Spain: SEFH; 2015. p 257.

41. Corregidor-Luna L, Salcedo Mingoarranz AL, Legaria Gaztambide E, Suárez Del Olmo D, Santos Mena B, García Díaz B. Impacto económico de la optimización e intensificación de tratamientos biológicos en Psoriasis. Farm Hosp. 2016;627[Suppl 1]:18-296.

42. Rentero-Redondo L, Iniesta Navalón C, González Molina R, Villalón Plá MJ, García-Villalba Sánchez $\mathrm{F}$, Antequera Lardón M. Integración del farmacéutico en el equipo multidisciplinar reumatología-farmacia: un paso hacia la individualización de la terapia biológica. Farm Hosp. 2016;40:296.

43. Rosado AA, Herrero-Muñoz N, Romero-Matea A, Horcajada-Reales C, Fernandez-Roman AB, PouAlonso A et al. Swithcing entre etanercept producto de referencia y su biosimilar: resultados en salud e impacto económico. In: Congreso Comunicaciones 62 congreso de la Sociedad Española de Farmacia Hospitalaria (SEFH). Madrid, Spain: SEFH; 2017. p 696.

44. Heinen-Kammerer T, Daniel D, Stratmann L, Rychlik R, Boehncke WH. Cost-effectiveness of psoriasis therapy with etanercept in Germany. J Dtsch Dermatol Ges. 2007;5(9):762-8.

45. Spandonaro F, Ayala F, Berardesca E, et al. The cost effectiveness of biologic therapy for the treatment of chronic plaque psoriasis in real practice settings in Italy. BioDrugs. 2014;28(3):285-95.

46. Vallejo-Torres L, García-Lorenzo B, Castilla I, et al. Valor Monetario de un Año de Vida Ajustado por Calidad: Estimación empírica del coste de oportunidad en el Sistema Nacional de Salud. Ministerio de Sanidad, Servicios Sociales e Igualdad. Servicio de Evaluación del Servicio Canario de la Salud: Informes de Evaluación de Tecnologías Sanitarias. 2015. http://www3.gobiernodecanarias.org/sanidad/ scs/contenidoGenerico.jsp?idDocument=e690e0c1cbed-11e5-a9c5-a398589805dc\&idCarpeta=ce590e 
62-7af0-11e4-a62a-758e414b4260. Accessed 23 Oct 2017.

47. Sacristán JA, Oliva J, Del Llano J, Prieto L, Pinto JL. ¿Qué es una tecnología sanitaria eficiente en España? Gac Sanit. 2002;16:334-43.
48. Husereau D, Drummond M, Petrou S, et al. Consolidated Health Economic Evaluation Reporting Standards (CHEERS) - explanation and elaboration: a report of the ISPOR Health Economic Evaluation Publication Guidelines Good Reporting Practices Task Force. Value Health. 2013;16(2):231-50. 